\title{
ASPECTOS SOCIOCULTURAIS DA ALIMENTAÇÃO DA POPULAÇÃO RESIDENTE EM MUNICÍPIOS DE PEQUENO PORTE, NO SUDOESTE DO PARANÁ
}

\author{
Karoline Fontana Simon ${ }^{1}$
}

Thais de Oliveira ${ }^{2}$

Rozane Toso Bleil ${ }^{3}$

RESUMO: O mercado da alimentação está crescendo paralelamente à evolução do processo urbano-industrial, por conta disso, a alimentação da população em geral, vem sofrendo transformações. Trata-se de uma pesquisa exploratória sobre a cultura alimentar da população dos municípios de Ampére e Santa Izabel do Oeste. O objetivo deste estudo foi identificar as referências alimentares da população acima descrita conforme se apresenta hoje. A coleta de dados foi realizada por meio de entrevista com pessoas que tinham em seu cotidiano uma proximidade com as questões alimentares. A organização das entrevistas foi feita com base na Análise de Conteúdo e posteriormente analisadas pela técnica do Discurso do Sujeito Coletivo. Os resultados ressaltam o conhecimento dos entrevistados em relação à cultura alimentar local. As transformações causadas pela globalização e mudanças que acabaram ocorrendo, modificaram as preferências alimentares na população residente nestes municípios. Palavras-chave: Segurança alimentar. Cultura alimentar. Hábitos alimentares.

\section{SOCIO-CULTURAL ASPECTS OF FOOD IN POPULATION FROM SMALL MUNICIPALITIES IN THE SOUTH WEST OF PARANÁ}

\begin{abstract}
The food market is growing in parallel with the evolution of the urban-industrial process, because of this, the food of the population in general, has undergone transformations. It is an exploratory research on food culture of the population of the municipalities of Ampere and Santa Izabel do Oeste. In order to identify the power of references of the population above as it stands today. Data collection was conducted through interviews with people who had in their daily closeness to the food issues. The organization of the interviews was based on content analysis and then analyzed by the technique of collective subject discourse. The results emphasize the knowledge of the respondents in relation to the local food culture. The changes caused by globalization and changes that ended up happening, modified food preferences in the population living in these municipalities.
\end{abstract}

Keywords:Food security. Food culture. Eating habits.

\section{ASPECTOS SOCIO-CULTURALES DE LA ALIMENTACION DE POBLACIÓN RESIDENTE EN MUNICIPIOS PEQUEÑOS, EN EL SUDOESTE DEL PARANÁ}

RESUMEN: El mercado de la alimentación está creciendo paralelamente a la evolución del proceso urbanoindustrial, por cuenta de ello, la alimentación de la población en general, viene sufriendo transformaciones. Se trata de una investigación exploratoria sobre la cultura alimentaria de la población de los municipios de Ampére y Santa Izabel do Oeste. El objetivo de este estudio fue identificar las referencias alimentarias de la población arriba descrita conforme se presenta hoy. La recolección de datos fue realizada por medio de entrevistas con personas que tenían en su cotidiano una proximidad con las cuestiones alimentarias. La organización de las entrevistas fue hecha con base en el Análisis de Contenido y posteriormente analizadas por la técnica del Discurso del Sujeto Colectivo. Los resultados resaltan el conocimiento de los entrevistados en relación a la cultura alimentaria local. Las transformaciones causadas por la globalización y los cambios que acabaron ocurriendo, modificaron las preferencias alimentarias en la población residente en estos municipios.

Palabras Llave: Seguridad alimentaria. La cultura alimentaria. Hábitos alimenticios.

\section{Introdução}

A alimentação constitui uma das atividades humanas de maior importância, não somente por razões biológica, mas também por envolver aspectos econômicos, sociais, científicos,

\footnotetext{
${ }^{1}$ Graduada em Nutrição pela Universidade Federal da Fronteira Sul.

${ }^{2}$ Graduada em Nutrição pela Universidade Federal da Fronteira Sul.

${ }^{3}$ Doutora em Alimentos e Nutrição pela Universidade Estadual de Campinas, (2009). Professora da Universidade Federal da Fronteira Sul.
} 
políticos, psicológicos e culturais fundamentais na dinâmica da evolução das sociedades (PROENÇA, 2010).

No Brasil, os estudos sobre alimentação, ressaltando a cultura e a história, tiveram início na década de 1930 com Josué de Castro, mapeando a fome e carências nutricionais por regiões e Luis da Câmara Cascudo que levantou hábitos alimentares e costumes do brasileiro. No Paraná, foi Carlos Roberto Antunes dos Santos, atualmente professor da Universidade Federal do Paraná, quem desenvolveu os primeiros estudos sobre alimentação na região, dentro de uma perspectiva histórica (DANSKI, 2008).

Teixeira (2015) salienta que no mundo contemporâneo é possível identificar mudanças na cultura alimentar por consequência da preocupação com a saúde, falta de tempo e pelas crescentes transformações nos hábitos alimentares ocasionadas pelo processo de globalização. Para tanto, a alimentação é um fenômeno coletivo, além de ser uma necessidade biológica humana, que é culturalmente influenciado e vivenciado pelo indivíduo.

Diez (2003) ressalta que se por um lado tal processo de globalização amplia a diversidade alimentar, pelo outro à reduz, uma vez que circula um mesmo leque de opções alimentares próprias da globalização. Ocasionando assim, possíveis mudanças no repertório culinário de referência regional, elencando a importância de se investigar, para melhor se delinear a comensalidade atual e assim aprofundar o conhecimento sobre o que determina esses novos padrões.

Atualmente na sociedade em que se vive cada vez mais integrada pela informação e pela economia, é quase impossível que a cultura também não sofra os efeitos desta modernização. Pensando nesta perspectiva, o objetivo deste estudo foi identificar os aspectos socioculturais ligados as referências alimentares, a fim de compreender a percepção da população dos Municípios de Santa Izabel do Oeste e Ampére, em relação à esta temática.

\section{Metodologia}

Primeiramente realizou-se um levantamento bibliográfico detalhado sobre a história e cultura alimentar da população do Paraná, da região Sudoeste e principalmente, da microrregião de Capanema.

A pesquisa foi realizada nos municípios de Santa Izabel do Oeste e Ampére localizados no sudoeste do Paraná. Santa Izabel possui 13.132 habitantes segundo o censo do Instituto Brasileiro de Geografia e Estatística - IBGE (2010) e foi criado em 1963, quando foi desmembrado dos municípios vizinhos de Realeza e Ampére. O município de Ampére, conta com uma população de 17.308 habitantes segundo o censo do Instituto Brasileiro de Geografia e 
Estatística - IBGE (2010), sendo emancipado em 11 de abril d 1961. Os dois municípios possuem 14,2 km de distância entre eles.

A coleta dos dados realizou-se por meio de entrevistas, aplicadas previamente em um teste piloto, para comprovar se estavam de acordo com o objetivo da pesquisa.

O percurso teórico-metodológico desse estudo foi apoiado na abordagem qualitativa, proposta por Minayo (2004) realizada por meio de entrevistas individuais.

A pesquisa qualitativa segundo Alves-Mazzotti; Gewandsznajder (2001) tem caráter exploratório, onde estimula os entrevistados a pensarem livremente sobre algum tema, objeto ou conceito. Mostra aspectos subjetivos e atinge motivações não explícitas, ou mesmo conscientes, de maneira espontânea. Ela é utilizada quando se busca percepções e entendimento sobre a natureza geral de uma questão, abrindo espaço para a interpretação.

É uma pesquisa indutiva, isto é, o pesquisador desenvolve conceitos, ideias e entendimentos a partir de padrões encontrados nos dados, ao invés de coletar dados para comprovar teorias, hipóteses e modelos pré-concebidos (ALVES-MAZZOTTI; GEWANDSZNAJDER, 2001).

Como critério de seleção dos sujeitos, foi solicitado para três entidades dos dois municípios (Prefeitura, Associação Comercial e Empresarial/Industrial e Igreja com maior número de fiéis no município), que citassem nomes de pessoas que tivessem o maior tempo de permanência na comunidade local e que se encaixassem nos segmentos definidos.

Desta forma foi estabelecido que primeiramente seria selecionado o nome mais citado pelas três entidades determinadas. Em caso de mais de um indicado seria realizado sorteio dos nomes, e como terceira opção seria escolhido àquele que fosse indicado apenas uma vez, em determinado segmento.

Os sujeitos-alvo da pesquisa foram representantes pelos seguintes segmentos: saúde, educação, indústria, agricultura, poder público, comércio, alimentação, alimentação escolar e pioneiro. O recorte desses sujeitos levou em consideração o fato de se constituírem elementoschave no processo de formação de hábitos e memórias alimentares das cidades selecionadas para o estudo.

Conforme mostra a tabela 1, para efeitos de discussão dos resultados, estes sujeitos serão representados respectivamente por um número (representando o segmento) e pelas letras $\mathrm{A}$ (Ampere) e B (Santa Izabel do Oeste - SIO). 
Tabela 1: Representação dos municípios e segmentos participantes da pesquisa, 2014.

\begin{tabular}{l|l|l}
\hline \multicolumn{2}{l|}{ MUNICÍPIO } & SEGMENTO \\
\hline AMPERE - A & SANTA IZABEL DO OESTE - B & \\
\hline A1 & B1 & Saúde \\
\hline A2 & B2 & Educação \\
\hline A3 & B3 & Indústria \\
\hline A4 & B4 & Agricultura \\
\hline A5 & B5 & Poder Público \\
\hline A6 & B6 & Comercio \\
\hline A7 & B7 & Alimentação \\
\hline A8 & B8 & Alimentação Escolar \\
\hline A9 & B9 & Pioneiro \\
\hline
\end{tabular}

Fonte: Dados da Pesquisa. Elaborado pelas autoras.

Estabeleceu-se que cada sujeito escolhesse o local para realização das entrevistas. Para tanto, foi solicitado as entidades que dispusessem de uma sala, a qual seria usada, caso os entrevistados, não desejassem que a entrevista acontecesse nas suas próprias residências ou nos seus locais de trabalho.

As entrevistas foram seguidas de um roteiro a fim de que, nos dois municípios desta microrregião, as questões seguissem as mesmas linhas de raciocínio. $\mathrm{O}$ roteiro para a entrevista abordou questões sobre caracterização do sujeito, o sistema alimentar do município e a história alimentar, e ainda sobre segurança alimentar e nutricional.

Após a definição dos nomes entrou-se em contato com as pessoas, explicando o objetivo do projeto. As entrevistas foram realizadas com auxílio de gravadores, a fim de evitar equívocos que pudessem vir a acontecer na transcrição dos dados.

Esta pesquisa foi aprovada pelo Comitê de Ética em Estudos com Seres Humanos da Unioeste sob parecer n.122/2013-CEP. Todo indivíduo que participou voluntariamente das entrevistas, assinou o termo de compromisso, concordando com a divulgação dos dados, mantendo-se o sigilo dos nomes.

Após a transcrição dos dados, foi realizada a estruturação das respostas, sendo retiradas dos textos as expressões-chave, ou seja, partes de trechos ou mesmo transcrições literais do discurso, que revelaram a essência do depoimento, e que geralmente respondem à pergunta. A partir disso, foram identificadas as ideias centrais, que geralmente são um nome ou expressão 
que descreve de maneira mais sintética e precisa o sentido de cada um dos depoimentos analisados e de cada conjunto homogêneo.

\section{Resultados e Discussão}

As entrevistas nos municípios foram realizadas nos períodos de março a abril de 2013. Participaram do estudo dezesseis moradores, representantes dos segmentos, exceto o representante do setor alimentação de ambos os municípios, não puderam ser entrevistados.

Após a transcrição e leitura exaustiva das entrevistas, foram definidos os eixos temáticos que apresentaram a percepção dos moradores em relação as questões inicialmente propostas: história alimentar, segurança alimentar e sistemas alimentares. Abaixo segue a tabela 2 com os eixos temáticos definidos, os quais foram utilizados como base para análise das falas:

Tabela 2. Definição dos eixos temáticos a partir das análises das entrevistas realizadas. 2014.

\begin{tabular}{l|l}
\hline EIXO & TEMA \\
\hline $\mathbf{1}$ & Origem da comunidade \\
\hline $\mathbf{2}$ & Produção e comercialização agrícola \\
\hline $\mathbf{3}$ & Relação com meio ambiente \\
\hline $\mathbf{4}$ & Acesso a alimentação (segurança e insegurança alimentar) \\
\hline $\mathbf{5}$ & Consumo alimentar (cultura e hábito alimentar) \\
\hline $\mathbf{6}$ & Atenção à saúde \\
\hline
\end{tabular}

Fonte: Dados da Pesquisa. Elaborado pelas autoras.

Entre as respostas ouvidas muitos dos entrevistados repassaram respostas ricas, das quais foi possível conhecer melhor a história dos municípios.

A seguir serão analisadas e discutidas as falas dos sujeitos, por eixo identificado.

\section{Eixo 1: origem da comunidade.}

No geral, o relatado pelos moradores dos municípios de Ampere e Santa Izabel do Oeste mostra que, os pioneiros, em sua maioria, vieram oriundos principalmente de Santa Catarina e do Rio Grande do Sul. Os mesmos buscavam maiores oportunidades, e viam o Paraná como uma boa possibilidade, onde as terras ainda virgens, poderiam proporcionar o sustento futuro. É 
preciso ressaltar que quando os primeiros habitantes chegaram a esta localidade, toda a área era composta por matas, as quais foram derrubadas para fim de sustento dos mesmo que vieram em busca de novas oportunidades. Tal análise pode ser confirmada pelas falas a seguir:

"Foram moradores que vieram do Rio Grande do Sul, de Santa Catarina, e vieram pra cá a procura de terra para plantar, porque era tudo mato, então os primeiros moradores foram desbravando e no início faziam grupos de pessoas que vieram pra cá, e gostaram do local e daí foram povoando... e aqui foi explorado a madeira, vieram muitos madeireiros, do Rio Grande e Santa Catarina, explorando madeira e agricultura" (B2).

Em outro relato o entrevistado afirma que o município "se formou fazendo desbravamento, fazendo as lavouras, derrubando as matas e teve muitas queimadas para a sobrevivência. Os filhos trabalhavam muito guardando alimento de um ano para o outro para sobrevivência da família. Vieram a maioria da região Sul” (A9).

Briskievicz (2010) cita que a partir de 1940, foi o período em que houve a inserção dos migrantes descendentes de italianos, alemães e poloneses provenientes, sobretudo, do Rio Grande do Sul e de Santa Catarina na região do sudoeste do Paraná. Quando estes migrantes se fixavam nestas terras, por meio de aquisição das propriedades, mandavam notícias a seus parentes e amigos, informando-lhes das oportunidades de trabalho, e assuntos relacionados ao território, o que os incentivava a migrarem para esta região.

Os migrantes mantinham atividades relacionadas a culturas de subsistência e organização do trabalho familiar. A cultura e política deste local foram influenciadas pelos ancestrais europeus, vindos da Itália, Alemanha e Polônia. Vale realçar que nem todos reproduzem o mesmo modo de vida, sobretudo quando eclode novos conflitos em torno da terra (BRISKIEVICZ, 2010).

\section{Eixo 2: Produção e comercialização de produtos agrícolas}

Nota-se, que no município de Santa Izabel do Oeste as principais atividades econômicas atualmente são a produção leiteira, produção agrícola, avicultura e o comércio em geral. Em função desta informação, procurou-se saber sobre a produção, comercialização e o consumo destes alimentos.

"Existe a feira dos pequenos agricultores, onde eles produzem seus produtos e vendem na feira. Todos os finais de semana e tem bastante compradores" (A1).

Foi relatado nas entrevistas que, no início da colonização do município, a produção era basicamente a monocultura, produzindo somente o básico para a sobrevivência em minifúndios. Mas com o passar dos anos isso foi mudando, juntamente com as tecnologias do campo e a obtenção de latifúndios, como é possível perceber em algumas falas: 
É grande a produção de soja, milho, era também de fumo, uma preocupação muito grande com os agrotóxicos usados, mas me parece que essa produção está diminuindo. Mas também tem de leite, que é grande.... A soja é vendida para a região, normalmente vai para o porto de Paranaguá ou fábricas de óleo que tem na região. E o milho seria a Sadia e é uma das maiores empresas compradoras de milho e outras empresas que se estabeleceram na região e fazem comércio deste produto... a Prefeitura é parceira, tem incentivo e parcerias (A1).

Percebe-se que existem algumas diferenças entre os municípios neste eixo, como a presença de feiras em Ampére e a exportação de alimentos ali produzidos, diferente do município de Santa Izabel do Oeste, que não possui a venda de alimentos nas feiras e o que é produzido no município permanece para o próprio consumo da população. Não se produziria se não houvesse saída, e se essa produção é mantida no próprio município, os custos com transporte são diminuídos, além de que esses alimentos ficam para alimentar os próprios munícipes.

A estimativa de custos de produção agrícola tem assumido importância crescente, sendo que a eficiência de produção de determinado alimento está diretamente interligada com o custo da produção, bem como o destino e consumo do alimento que está sendo produzido (MARTIN et al, 1994).

\section{Eixo 3: Relação com meio ambiente.}

No eixo definido como relação com meio ambiente, foi abordada a questão da contaminação do ambiente, quando utilizados agrotóxicos e transgênicos na produção dos alimentos. Dentre todas as opiniões coletadas, nenhuma pessoa soube dizer o quão é prejudicial tanto para a saúde quanto para o ambiente o uso de transgênicos. Principalmente sobre esse assunto, por ser uma aplicação recente na agricultura, a falta de informações predomina na população. Esta análise pode ser confirmada por algumas falas:

É muito preocupante o uso de agrotóxicos, ele resolveu o problema dos produtores, mas criou um grande problema pra saúde das pessoas. Eu tenho o cuidado de comprar alimentos que dizem no mercado não ter agrotóxico, mas de uma forma ou outra todos tem (A1).

Segundo Souza (2013), a maioria da população brasileira se encontra perdida com as diferentes opiniões de especialistas quanto aos benefícios e malefícios trazidos ao homem pelos alimentos transgênicos. Neste contexto há indícios de que os brasileiros precisam estar em alerta quanto aos alimentos que consomem, tendo em vista os possíveis riscos e consequências que esses alimentos podem trazer para a sua saúde.

Quando o tema envolveu o uso de agrotóxicos na produção dos alimentos e no ambiente, todos os entrevistados conseguiram opinar, diferente de quando se tratava de transgênicos. A maioria dos entrevistados pensa como $\mathrm{H} 4$ : 
Produzir sem veneno, eu vejo que é quase uma utopia, mas racional sim, o que existe hoje, eu estava lá acompanhando ainda hoje, o pessoal que recolhe embalagens de agrotóxicos, é de se assustar da quantia de embalagens que tá sendo recolhida, estão usando cada vez mais, e tem que usar o mínimo possível. Com o passar dos anos está havendo muitas doenças, na verdura, na fruta, então algum tratamento você tem que fazer, mas se respeitar o tempo de tratamento e a carência, não vai fazer mal pra saúde do consumidor, o problema é aquele que se usa indiscriminado $(\mathrm{H} 4)$.

Stoppelli Magalhães (2005) ressaltam que muitos agrotóxicos repousam nas cascas das frutas e legumes. A grande maioria, no entanto, já age sistemicamente por toda a planta, inclusive nos frutos. A sanidade do alimento é um fator de qualidade que deve ser atestado por meio de certificação.

Pelas falas, percebe-se que não é uma escolha a utilização de alimentos produzidos transgenicamente ou com agrotóxicos. O consumo destes é feito por falta de opção e oportunidade, sendo que nos mercados dos municípios raramente se encontram produtos orgânicos, e quando encontrados os mesmos tem um preço maior como já citado.

Os cuidados com o meio ambiente ainda estão muito precários, porém, percebe-se, pelas entrevistas que existe um certo cuidado para diminuir os riscos de contaminação das águas. Também é comum o descarte de lixos em locais inadequados ainda falta conscientização da população com relação a isso, para que futuramente maiores riscos de contaminação sejam diminuídos e a poluição ambiental seja menor. Algumas falas a seguir mostram a preocupação de alguns com esta questão.

"Pra produzir tem que cuidar do meio ambiente, não poluir com tóxicos, e não produzir perto de águas. Porque quando coloca pode intoxicar a água. Na nossa região com certeza fazem" (A4).

"O meu marido é agricultor e eles estão tendo cuidado com os recipientes, eles se cuidam mais, pro produto também e o destino do recipiente. Eles devolvem os recipientes, tem certo tempo pra deixar limpinho e tem que devolver aonde comprou" (A8).

De acordo com a lei Lei $N^{o} 7.802$, de 11 de julho de 1989 , no Artigo $6^{\circ}, \S 2^{\mathrm{o}}$ :

Os usuários de agrotóxicos, seus componentes e afins deverão efetuar a devolução das embalagens vazias dos produtos aos estabelecimentos comerciais em que foram adquiridos, de acordo com as instruções previstas nas respectivas bulas, no prazo de até um ano, contado da data de compra, ou prazo superior, se autorizado pelo órgão registrante, podendo a devolução ser intermediada por postos ou centros de recolhimento, desde que autorizados e fiscalizados pelo órgão competente (BRASIL, 1989).

\section{Eixo 4: Acesso a alimentação (segurança e insegurança alimentar)}


Este eixo temático procurou-se perceber junto aos entrevistados como é o acesso a alimentação, considerando questões relativas a produção própria, aquisição, comercialização e consumo dos alimentos.

As respostas confirmam, na opinião dos entrevistados, que todos têm acesso a alimentação de forma satisfatória. Para Vasconcelos e Moura (2018) a segurança alimentar e nutricional consiste na realização do direito ao acesso a alimentos básicos, de qualidade, seguros e em quantidade suficiente, sem o intuito de comprometer outras necessidades essenciais, visando práticas alimentares saudáveis para a sobrevivência do individuo.

Quando questionados sobre o acesso a alimentação adequada, B3 ressaltou que "eu acho que a básica todo mundo tem acesso, porque se quiser economizar até num cantinho do lote pode produzir verdura pra você ter durante a semana".

Antigamente era tudo mais natural, plantava-se na roça trazia pra casa, plantava-se o milho levava para o moinho, para fazer a farinha no moinho, e o arroz também se descascava no moinho. Hoje em dia nem tem mais horta, até o pessoal da agricultura vem comprar na cidade, até galinha. Houve uma mudança brusca nesse sentido (A6).

Quando foi colocado em pauta o assunto segurança alimentar, os entrevistados, ficaram bastante pensativos, tentando encontrar a melhor resposta. Entre todas se destacaram algumas: "se alimentar de uma forma segura é você saber o que tá ingerindo..., ter certeza de onde que vem a origem dessa alimentação" (B5).

Para B3 a forma segura de se alimentar é com "alimentos orgânicos, sem agrotóxicos, a conservação desses alimentos, um cardápio adequado".

O conceito de alimentação adequada não está bem definido, são muitas informações que os leigos colhem de fontes inseguras e criam conceitos incertos, como notamos a seguir:

"Eu como de tudo, eu só cuido do carboidrato agora. De manhã, tomar café, comer uma bolacha, tomar leite. No almoço, arroz e feijão, uma carne e salada. E de tarde uma besteira, um chocolate, pouco, mas comemos" (A2).

Para B9 se alimentar de uma forma segura, "é procurar sempre ler os rótulos".

A insegurança alimentar (IA) existe quando a disponibilidade de alimentos nutricionalmente adequados e seguros, ou a capacidade para adquirir esses alimentos de forma socialmente aceitável, é limitada ou incerta. A insegurança alimentar pode variar do medo de não ser capaz de obter o alimento para saciar a fome em razão da escassez de alimentos (SILVA et al, 2012).

O Direito Humano à Alimentação Adequada é indispensável para a sobrevivência. As normas internacionais reconhecem o direito de todos à alimentação adequada e o direito 
fundamental de toda pessoa a estar livre da fome, como pré-requisitos para a realização de outros direitos humanos. Entretanto, o direito à alimentação adequada e o direito de estar livre da fome estão distantes da realidade de muitas pessoas em todo o mundo (BRASIL, 2010).

\section{Eixo 5: Consumo alimentar}

Este eixo procurou mostrar se as populações destas cidades ainda mantêm hábitos, cultura e costumes antigos, e se houve mudanças quais as que aconteceram. Quanto ao tipo de alimento mais consumido nas residências dos, nota-se que a grande maioria referiu consumir feijão e arroz.

B9 ressalta o que a maioria das pessoas consomem em suas casas, "aqui eu acredito, que na minha residência não é diferente das outras, tem a parte de farinhas né, que é o pão caseiro, massas, tem muito condimento, carne, enfim, o básico, arroz e feijão também”.

Nós ainda temos uma cultura muito boa, que é a cultura do feijão e arroz, você vê muitas famílias, mesmo na rotina desgastante, mesmo que leve a marmita hoje né, que é a rotina de quase todo mundo que come fora, ainda tem o habito do feijão e arroz, a mandioca, ainda temos esses três alimentos como a base da alimentação da população do município (B1).

Uma das questões mais evidentes sobre a alimentação atual é o processo de distanciamento humano em relação aos alimentos, onde a própria industrialização é percebida como um processo que pode distanciar o alimento das pessoas. A história da alimentação humana reflete que a preocupação constante com a busca/produção de alimentos vem passando por modificações tanto na forma de produzir quando de distribuir os alimentos (PROENÇA, 2010). Outro aspecto levantado durante as entrevistas foi o tipo de alimento que não poderia ser consumido, que de alguma forma seria prejudicial à saúde. E dentre as respostas, destaca-se a fala de B3 o qual ressalta que "na verdade pode comer tudo, o que não pode é os excessos, tem que ter uma noção daquilo que faz bem à saúde e daquilo que não pode comer em excesso que pode prejudicar a saúde da pessoa”.

E a realidade atual já esperada, foi traduzida pela resposta do H6 "a alimentação hoje com certeza teve mudanças, hoje é muito fast-food, coisa pronta, mas eu ainda mantenho uma alimentação correta devido que a minha esposa ainda fica em casa por causa dos filhos, daí eu almoço em casa".

Porém, a maioria dos entrevistados citou o processo de industrialização como prejudicial, pois tem se perdido o hábito de cultivar tudo em casa, justamente pela praticidade de se encontrar tudo pronto. 
"As pessoas comem muita besteira. Mais chocolate, tipo assim, arroz e feijão muito pouco. Chocolate, biscoito e frutas" (A3).

B2 ressalta que com o tempo a alimentação sofreu várias mudanças "a principal mudança da alimentação foi a industrialização, que antes a gente mesmo produzia, agora a gente compra desde o queijo, a banha o salame, a indústria caseira assim também, a gente mesmo fazia o sabão, hoje a gente compra”.

Para Silva et al (2012) no Brasil e em outros países, conceitos em torno da alimentação saudável têm sido delineados para contemplar o significado social e cultural da alimentação e as necessidades nutricionais dos diferentes grupos populacionais, de modo a dar suporte às ações que fomentam mudanças socioambientais em prol de escolhas alimentares mais saudáveis, tanto individual como coletivamente.

Atualmente deve-se estar com os alimentos processados e industrializados, tendo em vista que esses produtos têm tomado as prateleiras dos supermercados, e muitas vezes iludem o consumidor com propagandas enganosas, o que infelizmente tem aumentado o consumo destes alimentos nos últimos anos.

Outro aspecto marcante no município é a realização de festas típicas, onde reúnem várias pessoas, com o fim de preservar a cultura e os hábitos presentes envoltos das festas. Um dos entrevistados (B5) quando questionado sobre as festas do município relator que:

Tem bastante, um exemplo é o jantar italiano, que é mais voltando pra comida italiana mesmo, e festas de comunidade tem muitas, o CTG faz festas, o carreteiro ou outro tipo de comida, mas tudo voltado pro consumo mesmo, nenhuma promoção voltada pra uma alimentação saudável né, é aquele prato típico que vende, tem o cuidado é claro pra que seja uma alimentação boa, mas não se olha muito a questão das calorias, é o que realmente o povo gosta de consumir (B5).

Os entrevistados ressaltaram a importância da continuação destas festas típicas realizadas nos municípios, tendo em vista que há a apreciação da comida típica especifica de determinada festa, bem como a preservação e continuação cultural dos hábitos expostos e resgatados nestas festas. Para Mintz (2006, p.38) é possível enfatizar que a cultura alimentar é constituída pelos hábitos alimentares em um domínio em que a tradição e a inovação têm a mesma importância. Ou seja, a cultura alimentar não diz respeito apenas àquilo que tem raízes históricas, mas, principalmente, aos nossos hábitos cotidianos, que são compostos pelo que é tradicional e pelo que se constitui como novos hábitos.

Quando B4 foi questionado sobre cooperativas no município ele nos deu o exemplo da COAFE: 
A Coafe, pra entender como ela funciona, nós temos no município grupos de leite, organizados que produzem leite, tem a agroindústria que produz, e se cada um fosse se legalizar sozinho é inviável, então pegamos esse pessoal, produtores de leite, de alimentos, melado, de cachacinha, panificação, mel, criamos uma cooperativa que protege essas pessoas, e criamos uma marca, que é a VITABEL, então eles se legalizam via cooperativa, ela funciona tipo uma mãe pra eles, e através dela também é fornecido alimentos para o governo estadual, essa é a nossa cooperativa (B4).

Muitos entrevistados destacaram a importância da manutenção das associações, cujo objetivam ajudar principalmente os pequenos produtores, os quais tem menos condições de conseguirem produzindo individualmente. Juntamente com as cooperativas esses pequenos agricultores veem uma perspectiva de crescimento, onde toda a sua pequena produção é colocada no comercio, e com o tempo esses pequenos produtores incentivados podem se tornarem grandes produtos de alimentos, que serão consumidos para o sustento do próprio município.

\title{
Eixo temático 6: Atenção à saúde.
}

Nese eixo temático procurou-se conhecer os aspectos de saúde da população do município. Os entrevistados foram questionados sobre a existência no município de pessoas que passem fome, onde B1 respondeu sobre o que acha sobre pessoas passarem fome no município e foi bem critica a respeito dos programas de incentivo do governo para auxiliar os que precisam, ela ressalta que:

\begin{abstract}
Hoje com muito menos frequência, mas ainda encontramos muitas pessoas com dificuldades, algumas não vou dizer que porque querem, porque ninguém quer passar fome, mas talvez assim, por comodismo... Oportunidades tem, nós temos uma ascensão assim dentro do município, dentro do Brasil todo de industrias, de trabalho, existem disputas de trabalho né, o mercado de trabalho é extremamente competitivo... tem o bolsa família, bolsa daqui, dali, condiciona essas pessoas a viverem com um padrão de vida muito abaixo daquilo que eles poderiam viver. Eu sou muito crítica em relação à bolsa família e essas outras bolsas do governo porque, eu acho que alicia as pessoas a viverem mal, acondiciona eles a acostumarem a viver daquele pouquinho... eu acredito que a gente ta mudando essa realidade pouco a pouco mas ainda tem pessoas que infelizmente passam fome... (B1).
\end{abstract}

Para Turano e Almeida (2012, p. 52) os hábitos e preferências alimentares são aspectos fortemente arraigados, sendo que sua formação não se deve apenas ao sensório, mas sim à frequência diferenciada no consumo de certos alimentos, começando desde a tenra idade ao incentivar e formar o paladar da criança, envolvendo dessa forma, sentimentos regionalistas e recordações afetivas ligadas à família e ao meio social.

Já o B5 quando questionado se tinha o conhecimento de pessoas que passavam fome no município disse que: 
Certeza, nós estamos numa região muito carente, Santa Isabel não deixa de ser diferente, nós temos várias famílias que hoje digamos assim tem uma melhor alimentação até pelos incentivos do governo, mas ainda temos muitas famílias que ainda são privados da alimentação adequada, por não ter condições de estar adquirindo, espera-se que isso mude, uma bolsa família não resolve a situação de uma família, então ainda são situações sérias que ainda precisa de muito tempo pra resolver isso (B5).

Em seguida foi questionado sobre o que era mais presente no município, fome ou excesso de peso, sua resposta foi:

Da pra se dizer que as duas coisas, tem pessoas com fome, tem. O excesso de peso não quer dizer que você tenha, por exemplo, você pode ser obesa, comer pouco, mas come errado. Então tem as duas situações, a gente percebe ai o pessoal hoje preocupado em fazer caminhada, academia e outros, mas você vê pessoa obesas na classe mais humilde, quanto nas classes mais ricas, então o fator que pode estar levando a isso, não é só a falta de alimentação, e sim a alimentação inadequada (B5).

Por outro lado, notamos como o excesso de peso é frequente neste município também, os entrevistados justificam tal fato, pelo prazer que a comida oferece. "Seria a má alimentação, além, também, falta de cuidados com a própria saúde e também o uso excessivo de remédios também faz com que a pessoa adquira peso" (A1).

"Porque as pessoas não se controlam na alimentação. Eles só percebem pra fazer uma dieta, pra fazer alguma coisa quando ocorreu o fato, depois talvez já é tarde, deveria se precaver antes" (A5).

Mintz (2006, p. 36) enfatizava há anos atrás que conter a obesidade seria um desafio tão urgente para o Brasil quanto acabar com a fome. Sendo que por outro lado, o contingente com excesso de peso já ultrapassa a assustadora marca dos 70 milhões - cerca de $40 \%$ da população brasileira, não deixando dúvidas de que o Brasil que come mal é bem maior do que o Brasil que tem fome.

Os hábitos de vida dos brasileiros sofreram uma profunda mudança nos últimos anos, que estão provocando o aumento de doenças crônicas. Por isso Silva e Cárdenas (2007, p. 56) ressaltam que a alimentação desempenha na vida das pessoas um papel abrangente que envolve não apenas uma simples incorporação de material nutritivo necessário para a sobrevivência, mas algo que possui um profundo significado subjetivo, social e cultural.

\section{Conclusão}

Os resultados encontrados neste trabalho ressaltam o conhecimento dos entrevistados em relação à cultura alimentar, desde a emancipação até os dias atuais dos Municípios de Ampére e Santa Izabel do Oeste, onde as referências alimentares que a população mantém, foi repassada 
por seus pais e avós, considerando principalmente os alimentos produzidos e típico da região, estando estes hábitos presentes nesta cultura até hoje, independentemente da forte influência da globalização e industrialização observadas atualmente.

Percebe-se que a cultura alimentar está se se tornando semelhante em nível mundial, ou seja, os mesmos hábitos alimentares podem ser encontrados em distintos locais, como o consumo excessivo de alimentos industrializados comprometendo a saúde. Nota-se que os entrevistados têm pouco conhecimento sobre conceitos de segurança alimentar e nutricional, porém, tem conhecimento que uma má alimentação pode provocar danos na saúde humana, e consequentemente uma diminuição da qualidade de vida da população.

Portanto, salienta-se a importância da realização de ações de conscientização direcionada a população no sentido de preservar a cultura alimentar e promover a segurança alimentar e nutricional da população desta região, a fim de não perder a essência da cultura alimentar neste grupo.

\section{Referências}

ALVES-MAZZOTTI, AJ. GEWANDSZNAJDER, F. O método nas ciências naturais e sociais: pesquisa quantitativa e qualitativa. 2. ed. São Paulo: Pioneira, 2001.

DANSKI, MTR. História e alimentação: o advento do fast food em Curitiba. História Atual Online. Curitiba. n.17, p. 19-29, outubro, 2008.

DIEZ GARCIA, RW. Reflexos da globalização na cultura alimentar: considerações sobre as mudanças na alimentação urbana. Rev. Nutr. vol.16, n.4, p. 483-492, 2003. Disponível em: http://dx.doi.org/10.1590/S1415-52732003000400011. Acesso em: 16/06/2013.

MINTZ, Sidney W. Comida e antropologia: uma breve revisão. Revista Brasileira de Ciências Sociais. vol.16, n.47, p.31-42, outubro, 2011. Disponível em:

http://www.scielo.br/pdf/rbcsoc/v16n47/7718. Acesso em: 14/06/2013.

PROENCA, Rossana Pacheco da Costa. Alimentação e globalização: algumas reflexões. Ciência e Cultura. São Paulo, vol.62, n.4, p.43-47, outubro, 2010. Disponível em: http://cienciaecultura.bvs.br/scielo.php?script=sci_arttext\&pid=S0009-67252010000400014 Acesso em: 09/05/2018.

RAMOS, M. STEIN, L M. Desenvolvimento do comportamento alimentar infantil. Jornal de Pediatria, Porto Alegre, p. 229-237, maio, 2000. Disponível em: http://www.rebrae.com.br/artigo/comportamento_alimentar.pdf Acesso em: 15/07/2013.

SILVA, C. et al. Associação entre consumo alimentar e (in)segurança alimentar e nutricional em São José dos Ramos - PB. Braz. J. Food Technology. São José Dos Ramos, vol.23, p. 23-30, maio, 2012. Disponível em: http://www.scielo.br/pdf/bjft/v15nspe/aop_15e0105.pdf Acesso em: $14 / 10 / 2013$.

SILVA, V P. CÁRDENAS, C J. A comida e a sociabilidade na velhice. Revista Kairós. São Paulo, vol.10, n.1, p.51-69, 2007.

SOUZA, J. V. S. Percepção dos consumidores do Distrito Federal sobre alimentos transgênicos. Dissertação (Mestrado em Agronegócios) — Universidade de Brasília, Brasília, 2013. 
STOPPELLI, I M B S. MAGALHAES, C P. Saúde e segurança alimentar: a questão dos agrotóxicos. Ciência e saúde coletiva. Rio de Janeiro, vol.10, p. 91-100, dezembro, 2005. Disponível em: http://dx.doi.org/10.1590/S1413-81232005000500012 Acesso em: 14/10/2013.

TEIXEIRA, Camila. A influência da globalização na cultura alimentar. VI Congresso Nacional de Administração e Contabilidade, Rio de Janeiro, out. 2015.

TURANO, W. ALMEIDA, C C C. Educação Nutricional. In: Gouveia ELC. Nutrição Saúde \& Comunidade. 2. Ed. Rio de Janeiro: Revinter; 2012. p.57-77.

VALENTE, F L S. Direito humano à alimentação: desafios e conquistas. São Paulo: Cortez, 2002.

VASCONCELLOS, Ana Beatriz Pinto de Almeida. MOURA, Leides Barroso Azevedo de. Segurança alimentar e nutricional: uma análise da situação da descentralização de sua política pública nacional. Cadernos de Saúde Pública. Rio de Janeiro, vol.34, n.2, Disponível em: http://dx.doi.org/10.1590/0102-311x00206816. Acesso em: 09/05/2018.

YASBEK, M C. O programa Fome Zero no contexto das políticas sociais brasileiras. São Paulo em Perspectiva. São Paulo, vol.18, n.18, p. 104-112, junho, 2004. Disponível em:

http://dx.doi.org/10.1590/S0102-88392004000200011. Acessado em: 12/10/2014. 